Continuum Damage Mechanics Based Modeling of Fiber Reinforced Concrete in Tension

\author{
by \\ Faming Li and Zongjin Li \\ Department of Civil Engineering \\ The Hong Kong University of Science and Technology \\ July 21, 1999 \\ Revised Version
}

Submitted to The International Journal of Solids and Structures, July 1999. 


\title{
Continuum Damage Mechanics Based Modeling of Fiber Reinforced Concrete in Tension
}

\author{
Faming $\mathrm{Li}^{*}$ and Zongjin $\mathrm{Li}^{\dagger}$ \\ Department of Civil Engineering \\ Hong Kong University of Science and Technology \\ Clear Water Bay, Kowloon, Hong Kong
}

\begin{abstract}
The tensile properties of concrete can be enhanced substantially by incorporating high strength and small diameter short fibers which leads to fiber reinforced concrete (FRC). For this reason, FRC has been widely used in infrastuctures where tensile cracks may occur. However, an analytical model for such a material is still lacking. In this paper, an attempt was made to model the behavior of FRC shows a hardening response in tension, based on the Continuum Damage Mechanics (CDM). In the material, conventional concrete (a cement-sand-coarse-aggregate-water mix) was used as the matrix and short steel fibers were used as the reinforcement. The quasi-brittleness of the matrix and the fiber-matrix interfacial properties were taken into consideration. Results show that the model-predicted stress-strain curves agree well with those obtained experimentally.
\end{abstract}

\section{Introduction}

In a conventional FRC, the fiber content is usually within the range of $0.2-2 \%$ by volume (Zollo, 1997). At such a lower fiber content, the tensile response of FRC would assume a non-hardening type, which is characterized by the widening of a single crack,

"PhD, Department of Civil Engineering, Hong Kong University of Science and Technology, Clear Water Bay, Kowloon, Hong Kong. E-mail: celfm@ust.hk

†Author to whom correspondence should be addressed. Assistant Professor, Department of Civil Engineering, Hong Kong University of Science and Technology, Clear Water Bay, Kowloon, Hong Kong. E-mail: zongjin@ust.hk 
assume a non-hardening type, which is characterized by the widening of a single crack, similar to an un-reinforced concrete $(\mathrm{Li}, 1998)$. It has been reported that strain hardening and multiple cracking behavior can be achieved when aligned continuous fibers were used in the composite (Aveston et al., 1971; Li et al., 1992). Such a phenomenon was also observed in cementitious composites containing a higher volume fraction (say, $8 \%$ ) of randomly distributed short fibers (Naaman and Homrich, 1989). Analytical models of this kind of behavior were also developed (Li and Leung, 1992). In these composites, the fibers can, during loading, provide sufficient bridging forces to suppress crack opening and strain localization, and to yield multiple cracks. It should be pointed out, however, that the matrix of the investigated composite was either cement paste, mortar or cementitious slurry. Coarse aggregates were not incorporated.

Recently, it has been reported that FRC containing short fibers can also achieve a strain hardening type response when fiber content is high enough, in which conventional concrete was used as the matrix and short steel fibers were used as the reinforcement (Li et al., 1998). For these FRCs, since the concrete matrix is a quasi-brittle material, which is mechanically different from a cement paste or mortar matrix that can be approximated as a brittle material, the conventional linear elastic fracture mechanics or micromechanics cannot be directly applied to model their behavior (Shah et al., 1995).

In this paper, a nonlinear analytical model based on the concept of CDM is developed to characterize the tensile stress-strain response of FRC. A parallel bar arrangement of the composite is first used to establish the equilibrium equation. A basic governing equation is then derived coupling with the damage law of the matrix and that of the fibers. The damage evolution is then evaluated by considering the damage evolution of the matrix concrete and that of the fiber-matrix interface, respectively. Numerical results obtained from the constitutive equations of this model are compared to those obtained from experimental investigations. 


\section{The Analytical Model}

Since the mechanical response of an FRC is closely related to the nucleation and progression of a multitude of microcracks in the matrix, the Continuum Damage Mechanics (CDM) provides a possibly suitable method for developing an analytical model of the mechanical behavior of an FRC. The concept of CDM has been successfully applied to plain concrete (see, e.g., Karihaloo and Fu, 1990a; Karihaloo and Fu, 1990b; Løland, 1980; Mazars and Pijaudier-Cabot, 1989). Attempts have also been made to apply this concept to the modeling of a fiber reinforced concrete (see, e.g., Borderie et al., 1992; Fanella and Krajcinovic, 1985; Stang, Tonnesen and Byskov, 1990). A one-dimensional analytical model for the direct tensile response of an FRC based on the concept of CDM will be described in this paper. It is assumed that before the matrix damage is initiated, the material behaves as a two-phase composite material. As deformation increases, the matrix and the fiber will undergo independently different damage processes: the matrix concrete responds as a plain concrete, whereas the damage of the fiber evolves with the fiber debonding, slip and pull-out of the matrix. Thus, the damage in the cross-section is measured by the loss of the cross-sectional "area" of the matrix and the bond variation of the fiber-matrix interface.

The parallel bar model has been previously employed in the study of plastic and brittle behavior of materials (Krajcinovic and Silva, 1982). It has also been used to analyze the mechanical behavior of fiber reinforced concrete by Fanella and Krajcinovic (1985). In that model, it is assumed that once the tensile stress in the matrix is higher than its tensile strength, the tensile load of the composite bar is transmitted to the fibers alone, which implies that the matrix is a purely brittle material. This is not the case for FRC using conventional concrete as the matrix. Therefore, in applying the 
model to the analysis of FRCs, it has to be modified because of the quasi-brittleness of the concrete matrix.

Consider the parallel bar model shown in Fig. 1. In the figure, $L$ is the length of the specimen for a single cracking system, or the crack spacing for a multiple cracking system. Every bar is a completely elastic composite until the matrix damage is initiated. After the initiation of the matrix damage, the stiffness of such a bar decreases progressively, due to the stiffness reduction of the matrix as well as the fiber debonding and slip.

Thus, the force $f_{i}$ in the $i$ th bar is

$$
\begin{array}{lll}
f_{i}=\frac{k_{c} z}{N} & \text { for } 0 \leqslant k_{c} z \leqslant f_{m} \text { and } z \geqslant 0 & K_{c} \\
f_{i}=\frac{k_{d} z}{N} & \text { for } k_{c} z \geqslant f_{m} \text { and } z \geqslant 0 & K_{d}
\end{array}
$$

in which $N=$ the number of composite bars; $k_{c} / N=$ a constant, the stiffness of each of $N$ composite bars in which no damage occurred; $k_{d} / N=$ the stiffness of the bar in which the matrix has damaged, which is a random variable; $f_{m}=$ the force at which the matrix damage is initiated, and $z=$ the extension of the total specimen due to the active force $\mathrm{F}$.

Consider the force and deformation in each of the composite bars in which the matrix has damaged. A parallel model, as has been commonly used in the composite law, is assumed for the damaged matrix and the fibers, as shown in the enlarged part of Fig. 1. However, the fiber-matrix interface is no longer "perfectly bonded", because of the fiber debonding and sliding. Suppose the elongation due to the fiber (debonding and sliding) is $\alpha_{1} z$ and that due to the matrix is $\alpha_{2} z$, then we have

$$
f_{i}=\frac{k_{f}^{\prime} \alpha_{1} z}{M N}+\frac{k_{m} \alpha_{2} z}{M S}
$$


where $k_{f}^{\prime}=$ an equivalent stiffness of the fiber that elongates $\alpha_{1} z$, including the elastic elongation and the slip from the matrix; $k_{m}=$ the stiffness of the damaged matrix, which is a random variable depending upon the damage accumulation. $M=$ the total number of fibers in each of the $N$ composite bars; $S=$ total number of matrix bars in each of the $N$ composite bars; $\alpha_{1}$ and $\alpha_{2}$ are coefficients reflecting the deformation components of the fiber and the matrix, respectively, which will be discussed later. Note that $\alpha_{1} \neq \alpha_{2}$ in this model.

The equilibrium of forces in the vertical direction yields

$$
F=\sum_{n+1}^{N} \frac{k_{c} z}{N}+\sum_{1}^{n}\left[\sum_{m+1}^{M} \frac{k_{f}^{\prime} \alpha_{1} z}{N M}+\sum_{s+1}^{S} \frac{k_{m} \alpha_{2} z}{S M}\right]
$$

in which $n=$ the number of composite bars in which the matrix has damaged; $m=$ the number of fibers that failed due to debonding and pull-out in the damaged matrix; and $s=$ the number of damaged matrix bars. The first term on the right hand side of Eq. (4) represents the contribution of the integral (undamaged) part of the composite crosssection while the second term reflects the tensile force carried by the fibers spanning the damaged matrix and the quasi-brittleness of the matrix (for a brittle matrix, the last term can be assumed zero, as has been done by Fanella and Krajcinovic 1985).

Eq. (4) can be further written as

$$
F=k_{c} z\left(1-\omega_{c}\right)+k_{f}^{\prime} z \alpha_{1} \omega_{c}\left(1-\omega_{f}\right)+k_{m 0} z \alpha_{2} \omega_{c}\left(1-\omega_{c}\right)^{2}
$$

in which

$$
\omega_{c}=\frac{n}{N} \approx \frac{s}{S}, \quad \omega_{f}=\frac{m}{M}
$$

$k_{m 0}=$ the stiffness of the matrix material before damage, and

$$
k_{m}=k_{m 0}\left(1-\omega_{c}\right)
$$


$\omega_{c}$ and $\omega_{f}$ are the logical choices for the measure of damage accumulated in the crosssection of the FRC specimen, which denote the damage of the composite due to the matrix damage and the fiber damage (debonding and pullout), respectively. In Eq. (6), it is assumed that the fibers and aggregates are uniformly distributed in the composites.

The continuum form of Eq. (5) can thus be readily recovered by setting $F=\sigma A_{c}$, $k_{c}=E_{c} A_{c} / L, k_{f}^{\prime}=\beta_{f} k_{c}, k_{m 0}=\beta_{m} k_{c}$, and $z=\varepsilon L$ in which $\sigma=$ nominal stress. The term $\varepsilon$ is the nominal strain, and $\beta_{f}$ and $\beta_{m}$ are the stiffness ratios. Thus

$$
\sigma=E_{c}\left[\left(1-\omega_{c}\right)+\beta_{f} \alpha_{1} \omega_{c}\left(1-\omega_{f}\right)+\beta_{m} \alpha_{2} \omega_{c}\left(1-\omega_{c}\right)^{2}\right] \varepsilon
$$

A clear implication 'can be seen from Eq. (8) that when $\omega_{c}=0$, or no damage is initiated, $\sigma=E_{c} \varepsilon$, i.e., the composite behaves elastically; when $\omega_{c}=1$, or matrix is completely failed, $\sigma=E_{c} \beta_{f} \alpha_{1}\left(1-\omega_{f}\right) \varepsilon$, the contribution of the matrix disappeared; and when $\omega_{c}=\omega_{f}=1$, or both the matrix is completely failed and the fibers are completely pulled out, $\sigma=0$, i.e., the composite cannot bear any load. Therefore, a rational stress-strain relationship would be obtained by this model.

\section{Evolution of Damage}

\subsection{Evolution of $\omega_{c}$}

Damage $\omega_{c}$ can be characterized by the cumulative degradation in the load carrying capacity of the matrix. As mentioned earlier, $\omega_{c}=0$ denotes no damage in the matrix, while $\omega_{c}=1$ represents that the matrix failed completely. Therefore, $\omega_{c}$ can be approximately represented by considering the damage evolution of the matrix concrete.

There are a lot of CDM-based models for plain concrete. To make things not too complicated, a simple local approach proposed by Løland (1980) will be used in this paper. However, a minor modification is made to accommodate the present study. 
Assume that there is no damage below a strain level $\varepsilon_{0}$. The damage evolution is evaluated as

$$
\omega_{c}= \begin{cases}0 & \text { for } \varepsilon<\varepsilon_{0} \\ B_{1}\left(\varepsilon-\varepsilon_{0}\right)^{\xi} & \text { for } \varepsilon_{0} \leqslant \varepsilon \leqslant \varepsilon_{t} \\ \omega_{c t}+B_{2}\left(\alpha_{2} \varepsilon-\varepsilon_{t}\right) & \text { for } \varepsilon_{t}<\varepsilon \leqslant \varepsilon_{u} / \alpha_{2 m} \\ 1 & \text { for } \varepsilon_{m}>\varepsilon_{u} / \alpha_{2 m}\end{cases}
$$

in which $\varepsilon$ is the composite strain, $\alpha_{2 m}$ is a $\alpha_{2}$ when a matrix strain $\varepsilon_{m}$ reaches $\varepsilon_{u}$ (fictive ultimate strain), where $\varepsilon_{m}$ is the strain of the matrix concrete. $\varepsilon_{0}$ is the strain at which damage is initiated, $\varepsilon_{t}$ is the strain corresponding to the tensile strength, $f_{m t}$, of the concrete, and ' $\omega_{c t}$ is the damage of concrete corresponding to a strain of $\varepsilon_{t}$. $\omega_{c t}$ and the constants $B_{1}, B_{2}$, and $\xi$ can be determined by

$$
\begin{aligned}
& \omega_{c t}=1-\frac{f_{m t}}{E_{m 0} \varepsilon_{t}} \\
& \xi=\frac{\zeta}{(1-\zeta) t}, \quad B_{1}=\frac{1}{1+\xi t}\left(\varepsilon_{t}-\varepsilon_{0}\right)^{-\xi}, \quad B_{2}=\frac{\zeta t}{\varepsilon_{t}}
\end{aligned}
$$

in which

$$
\zeta=\frac{f_{m t}}{E_{m 0} \varepsilon_{t}}, \quad t=\frac{\varepsilon_{t}}{\varepsilon_{u}-\varepsilon_{t}}
$$

The damage evolution and the stress-strain curve are roughly shown in Fig. 2. The denotations of $\varepsilon_{0}, \varepsilon_{t}, \varepsilon_{u}$, and $\omega_{c t}$ can be found in that figure. In the above equations for $\omega_{c}$, there are five essential parameters, namely, $E_{m 0}, f_{m t}, \varepsilon_{0}, \varepsilon_{t}$, and $\varepsilon_{u}$. Except for $\varepsilon_{u}$, which is a fictive ultimate strain, all other parameters can be determined from the experimentally obtained stress-strain curves in a direct tensile test. Løland (1980) argued that the energy ratio between the specific energy consumed in microcrack formation within the whole strained body (length $L$ ), and that consumed 
in further cracking of the fracture zone (with extension of $D_{\max }$ ), remains constant, and independent of the water-cement, and aggregate-cement ratios used. This assumption leads to

$$
\varepsilon_{u}=\frac{2}{R} \frac{D_{m a x}}{L}\left(\varepsilon_{t}-\frac{f_{m t}}{E_{m 0}}\right)+\varepsilon_{t}
$$

in which $R$ is the aforementioned energy ratio, which can be determined from experiments.

\subsection{Evolution of $\omega_{f}$}

Damage $\omega_{f}$ characterizes the damage of the fiber in a composite bar of damaged matrix, namely, the fraction of fibers that are debonded and pulled out. If no fiber is debonded, the fiber and the matrix underwent a same deformation. If all fibers are debonded and pulled out, the composite bar fails completely.

Damage $\omega_{f}$ can therefore be related to the fiber debond length $a$ and fiber embedment length $\bar{\ell}_{e}$ as

$$
\omega_{f}=\frac{a}{\bar{\ell}_{e}}
$$

where $\bar{\ell}_{e}$ is the mean fiber embedment length. From a statistical consideration, $\bar{\ell}_{e}=\ell / 4$ for a random fiber distribution, where $\ell$ is the length of the fiber.

Eq. (14) implies that when the fiber debond length $a=0$, no damage occurs, while for $a=\bar{\ell}_{e}$, the fiber is completely debonded and pulled out $\left(\omega_{f}=1\right)$. Therefore, damage $\omega_{f}$ can characterize the failure of the fiber due to the interface debonding and fiber pullout.

To evaluate the evolution of damage $\omega_{f}$, it is necessary to examine the fiber matrix interfacial behavior as well as the cumulative distribution of the fiber embedment length. A fiber-matrix interfacial model has been examined in detail by Stang 
et al (1990) in which the effect of the weak transition zone existing between ordinary Portland cement paste and the fiber was taken into consideration. In the model, it is assumed that a pre-debonded interface (interfacial crack) exists with a length $a$ (starting at where the fiber and matrix meet) in the fiber-matrix interface. The fiber with a constant cross-sectional area of $A$ (with a diameter of $d_{f}$ ) and Young's modulus of $E_{f}$ is embedded in the matrix with a mean embedment length of $\bar{\ell}_{e}$. The fiber axial displacement is denoted by $U$ and is assumed to be constant over the fiber cross section. The bonded zone is assumed to be elastic with a stiffness $k$, while the debonded zone is represented by a constant shear force $q_{f}$. The Poisson's ratio is neglected for both fiber and the boundary layer (i.e., the shear lag). According to this model, the displacement at the fiber free end $U^{*}$ can be written as

$$
U^{*}=\frac{q_{f} D}{E_{f} A \psi^{2}}+\frac{q_{f} \bar{\ell}_{e}^{2}}{2 E_{f} A}\left(\frac{a}{\bar{\ell}_{e}}\right)^{2}+\frac{q_{f} \bar{\ell}_{e} D}{E_{f} A \psi}\left(\frac{a}{\bar{\ell}_{e}}\right) \tanh \left[\psi \bar{\ell}_{e}\left(1-\frac{a}{\bar{\ell}_{e}}\right)\right]
$$

in which $D$ and $\psi$ are defined as

$$
D=\frac{1}{2}+\sqrt{\left(\frac{1}{2}\right)^{2}+\frac{2 \pi d_{f} k \Gamma}{q_{f}^{2}}}, \quad \psi=\sqrt{\frac{k}{E_{f} A}}
$$

and $\Gamma$ is the interface critical energy release rate.

At the applied load $F$, the damaged composite bar will elongate $z$. Before the matrix cracks, it can be assumed that there is no fiber slip in the matrix (although damage may have been initiated). Then the deformation of the matrix is approximately equal to the elongation of the composite, $z$, i.e., $\alpha_{2}=1$, and the contribution of fibers to the composite elongation can be neglected, or $\alpha_{1} \approx 0$. After the matrix cracks, $\alpha_{1}$ will normally be not equal to $\alpha_{2}$. The deformation of the fiber and the matrix can then be written as

$$
\begin{aligned}
& \alpha_{1} z=2 \cdot U^{*} \\
& \alpha_{2} z=\varepsilon_{m} \cdot L
\end{aligned}
$$


Combining Eqs. (17), (15) and (14), it can be obtained that

$$
\frac{L}{2} \cdot \alpha_{1} \varepsilon=\frac{q_{f} D}{E_{f} A \psi^{2}}+\frac{q_{f} \bar{\ell}_{e}^{2}}{2 E_{f} A} \omega_{f}^{2}+\frac{q_{f} \bar{\ell}_{e} D}{E_{f} A \psi} \omega_{f} \tanh \left[\psi \bar{\ell}_{e}\left(1-\omega_{f}\right)\right]
$$

provided that

$$
\varepsilon>\varepsilon_{0}^{f}=\frac{2 q_{f} D}{\alpha_{10} L E_{f} A \psi^{2}}
$$

which suggests that no damage related to fibers occurs before debonding is initiated. In Eq. (19), $\alpha_{10}$ is the $\alpha_{1}$ corresponding to the initial debonding strain $\varepsilon_{0}^{f}$. $\omega_{f}$ can be obtained numerically by solving Eq. (18).

Once $\omega_{c}$ and $\omega_{f}$ are determined, the continuum model can then be established through Eq. (8). Parameters related to the model will be discussed in the following section.

\section{Determination of the Parameters}

Several parameters have to be determined before the application of the derived model. These include: (1) stiffness ratios $\beta_{f}$ and $\beta_{m} ;(2)$ composite elastic modulus $E_{c} ;$ (3) length $L ;(4)$ the fiber-matrix interface parameters: $\psi, q_{f}$, and $\Gamma ;(5)$ the parameters related to matrix concrete: $\varepsilon_{0}, \varepsilon_{t}, \varepsilon_{u}, f_{m t}$, and $E_{m 0} ;(6)$ damage related to fibers $\omega_{f}$, and (7) coefficients $\alpha_{1}$ and $\alpha_{2}$;

\subsection{Stiffness ratios $\beta_{f}$ and $\beta_{m}$}

An exact estimation of $\beta_{f}$ will be very difficult, because the equivalent stiffness of the fiber varied during the process of fiber debonding and slipping. However, an average stiffness can be estimated by the following analysis. 
Consider a fiber with an average embedment length of $\ell / 4$ that bridges a transverse crack. One half of this embedment length is debonded, in a statistical sense, and the other half is perfectly bonded through elastic adhesional bond. The stress transfer between the fiber and the matrix will cause an average force build-up in the fiber, which can be derived as (set $a=\ell / 8$ ), according to the interface model (Stang, Li and Shah, 1990):

$$
\bar{P}_{f}=\frac{4 q_{f} D}{\psi^{2} \ell \cosh \frac{\psi \ell}{8}}\left[\cosh \left(\frac{\psi \ell}{8}\right)-1\right]+\frac{3 q_{f} \ell}{32}
$$

The average deformation in the fiber, by taking into consideration of the elastic deformation of the fiber only, can be derived as

$$
\bar{U}_{f}=\frac{4 q_{f} D}{E_{f} A \psi^{3} \ell}\left[1+\frac{3(\psi \ell)^{2}}{128}\right] \tanh \left(\frac{\psi \ell}{8}\right)
$$

The average equivalent stiffness for a single fiber can be therefore estimated as

$$
\frac{k_{f}^{\prime}}{M N}=\frac{\bar{P}_{f}}{\bar{U}_{f}}=\frac{E_{f} A \psi}{128+3(\psi \ell)^{2}}\left[128 \tanh \left(\frac{\psi \ell}{16}\right)+\left(\frac{3}{D}\right)(\psi \ell)^{2} \operatorname{coth}\left(\frac{\psi \ell}{8}\right)\right]
$$

The total number of fibers $M N$ in a composite cross section will be (for 2-D random distribution) (Hannant, 1978)

$$
M N=\frac{2 V_{f} A_{c}}{\pi A}
$$

Therefore,

$$
\begin{aligned}
\beta_{f} & =\frac{\ell}{2 \ell_{c}} \cdot \frac{k_{f}^{\prime}}{k_{c}}=\frac{\ell}{2 \ell_{c}} \cdot \frac{k_{f}^{\prime}}{E_{c} A_{c} / L} \\
& =\frac{\ell E_{f} V_{f} \psi L}{\pi E_{c} \ell_{c}\left(128+3 \psi^{2} \ell^{2}\right)}\left[128 \tanh \left(\frac{\psi \ell}{16}\right)+\left(\frac{3}{D}\right) \psi^{2} \ell^{2} \operatorname{coth}\left(\frac{\psi \ell}{8}\right)\right]
\end{aligned}
$$

in which a length efficiency factor $\ell /\left(2 \ell_{c}\right)$ is incorporated. 
The stiffness ratio $\beta_{m}$ can be estimated from its definition as

$$
\beta_{m}=\frac{k_{m 0}}{k_{c}}=\frac{A_{m} E_{m 0} / L}{A_{c} E_{c} / L}=\frac{E_{m 0}}{E_{c}}\left(1-V_{f}\right)
$$

\subsection{Composite Elastic Modulus $E_{c}$}

For a composite containing short aligned fibers, a "Rule of Averages" is used (see, Hull and Clyne, 1996) to derive the composite modulus, which can be expressed as

$$
E_{c}=V_{f} E_{f}\left[1-\frac{\tanh \left(n_{\tau} \ell / d_{f}\right)}{n_{r} \ell / d_{f}}\right]+\left(1-V_{f}\right) E_{m 0}
$$

However, for composite containing randomly distributed short fibers, Eq. (26) has to be modified. Taking account of the fiber orientation effect, $\eta$, Eq. (26) can be modified as

$$
E_{c}=\gamma V_{f} E_{f}+\left(1-V_{f}\right) E_{m 0}
$$

where

$$
\gamma=\eta\left[1-\frac{\tanh \left(n_{r} \ell / d_{f}\right)}{n_{r} \ell / d_{f}}\right]
$$

in which $\eta$ is the fiber orientation efficiency factor defined as (Bentur and Mindess, 1990):

$$
\eta= \begin{cases}\frac{1}{6} & \text { for fully random fibers in } 3-\mathrm{D} \\
\frac{1}{3} & \text { for random fibers in } 2-\mathrm{D} \\
\frac{1}{2} & \text { for planar mat with aligned fibers in } X Y \text { direction }\end{cases}
$$

and $n_{r}$ is a dimensionless constant given by

$$
n_{r}=\left[\frac{2 E_{m 0}}{E_{f}\left(1+\nu_{m}\right) \ln \left(1 / V_{f}\right)}\right]^{1 / 2}
$$


where $\nu_{m}$ is the Poisson's ratio of the matrix.

\subsection{Length $L$}

The length $L$ is the crack spacing in a multiple cracking system. The crack spacing is difficult to measure experimentally. Therefore, an analytical result is used instead in this study.

The ACK model (Aveston et al., 1971) for continuous aligned fiber composite assuming frictional stress transfer gives out a minimum crack spacing of

$$
\ell_{s}=\left(\frac{V_{m}}{V_{f}}\right) \frac{f_{m t} d_{f}}{4 \tau_{f u}}
$$

where $\tau_{f u}$ is the frictional bond strength of the fiber-matrix interface, and $f_{m t}$ is the tensile strength of the concrete matrix. After crack saturation (no further crack will be formed), a final crack spacing of between $\ell_{s}$ and $2 \ell_{s}$ is expected. An average crack spacing of $1.337 \ell_{s}$ is obtained by Kimber and Keer (1982).

Taking into consideration of the fiber length effect and the orientation effect (Bentur and Mindess, 1990), this average crack spacing becomes

$$
\begin{aligned}
L & =1.337\left(\frac{2 \ell_{c}}{\ell}\right)\left(\frac{\pi}{2}\right) \frac{V_{m}}{V_{f}} \frac{f_{m t} d_{f}}{4 \tau_{f u}} \\
& =1.050 \frac{\ell_{c}}{\ell} \frac{V_{m}}{V_{f}} \frac{f_{m t} d_{f}}{\tau_{f u}}
\end{aligned}
$$

where $\ell_{c}$ is the critical fiber length, which is given by

$$
\ell_{c}=\frac{\sigma_{f u} \cdot d_{f}}{2 \tau_{f u}}
$$

in which $\sigma_{f u}$ is the ultimate tensile strength of the fiber, which can be found in Table 1 for the fibers used in this study. 


\subsection{Interface parameters $\psi, q_{f}$, and $\Gamma$}

Numerous efforts have been made with respect to the fiber-matrix interfacial properties, both experimentally and analytically. The interface parameters $\psi, q_{f}$, and $\Gamma$ are therefore best determined based on experimental results. Unfortunately, there is no direct measurement of these parameters from the literature, and very few experimental investigations into hooked fibers (Dramix fibers in this study) were made. Therefore, these parameters were determined rationally based on previous studies (e.g., Bentur and Mindess, 1990; Gray, 1984; Li et al., 1991; Pompo et al., 1996). According to Li et al. (1991), parameter $\psi$ is a material property independent of fiber embedment length. Therefore, for Dramix steel fibers used in this study, the following values were used: $\psi=90 \mathrm{~m}^{-1}, \tau_{f u}=3.80 \mathrm{MPa}, q_{f}=\tau_{f u} \cdot \pi d_{f}=5969 \mathrm{~N} / \mathrm{m}, \Gamma=17.2 \mathrm{~N} / \mathrm{m}$.

\subsection{Matrix parameters $\varepsilon_{0}, \varepsilon_{t}, \varepsilon_{u}, f_{m t}$ and $E_{m 0}$}

The properties of the matrix concrete have been studied extensively. These parameters are determined from the experimental results of these studies. The results shown in Table 2 are obtained based on direct tensile tests on ten specimens which had mix proportions of C:W:S:A=1:0.45:2:0.65.

Note that $\varepsilon_{0}$ is measured as the strain corresponding to stress of $40 \% f_{m t}$ from the stress-strain curve. This is based on observations from the acoustic emission measurement that the microcracking is initiated at a stress of about $40 \% f_{m t}$, as described by $\mathrm{Li}$ (1998) and $\mathrm{Li}$ and $\mathrm{Li}$ (1999). Strain is measured as the average displacement over the gage length of the LVDT, where the average displacement is based on those detected by the two opposite LVDT transducers among which one of them is used as feedback control. In addition, a Possion's ratio $\nu_{m}=0.17$ is used for the matrix concrete, as shown by Gray (1984). 


\subsection{Damage Related to Fibers $\omega_{f}$}

The measure of damage related to fibers, $\omega_{f}$, is related to the composite strain by Eq. (18), from which $\omega_{f}$ can be solved numerically when $\varepsilon>\varepsilon_{0}^{f}$. An extreme value of $\varepsilon$ exists for Eq. (18), representing a moment at which successive fiber debonding will be terminated. The corresponding $\omega_{f c}$, a critical value representing the termination of successive fiber debonding beyond which adhesional bond is completely deteriorated, can be obtained by taking a first order derivative of Eq. (18) to $\omega_{f}$, and let it be zero as

$$
\begin{aligned}
& \omega_{f c} \cdot\left\{\tanh \left[\psi \bar{\ell}_{e}\left(1-\omega_{f c}\right)\right]\right\}^{2} \\
& +\frac{1}{\psi \bar{\ell}_{e}} \tanh \left[\psi \bar{\ell}_{e}\left(1-\omega_{f c}\right)\right]-\left(1-\frac{1}{D}\right) \cdot \omega_{f c}=0
\end{aligned}
$$

which can also be obtained numerically. The existence of a critical damage, $\omega_{f c}$, can be attributed to the ideal interface property assumption. When the bonded length of the fiber is reduced to a critical length, the adhesional bond will deteriorate completely such that only frictional bond exists. Therefore, $\omega_{f c}$ can be used as an indication of the maximum load the composite can carry.

\subsection{Coefficients $\alpha_{1}, \alpha_{2}, \alpha_{10}$ and Initial Debonding Strain $\varepsilon_{0}^{f}$}

As mentioned previously, coefficients $\alpha_{1}$ and $\alpha_{2}$ represent the composite deformation contribution from the fiber and from the matrix, respectively. It is not quite understood how much fractions of deformation are distributed for the two phases after the matrix cracks. However, the following boundary conditions have to be satisfied:
(1) $\alpha_{1} \approx 0, \quad \alpha_{2}=1 \quad$ for $\varepsilon \leqslant \varepsilon_{t}$
(2) $\alpha_{1} \leqslant 1, \quad \alpha_{2} \leqslant 1 \quad$ for $\varepsilon>\varepsilon_{t}$ 
which implies that before the matrix cracks, the fibers have approximately no contribution to the composite deformation. After that, they both contribute to the composite deformation.

Naaman and Homrich (1989) proposed an estimation of the strain capacity (peak point strain of the tensile stress-strain curve), $\varepsilon_{c a}$ as:

$$
\varepsilon_{c a}=\varepsilon_{u}+K V_{f} \frac{\ell}{d_{f}}
$$

in which $\varepsilon_{c a}$ is the strain at maximum tensile stress of the composite, $\varepsilon_{u}$ is the ultimate tensile strain of the unreinforced matrix, and $K$ is a constant depending on the fiber type, which has to be determined from experiments. Based on the experimental results from this study, $\varepsilon_{u}=406.3 \times 10^{-6}$ for matrix concrete, and

$$
K= \begin{cases}0.00099 & \text { for Dramix I steel fiber } \\ 0.00115 & \text { for Dramix II steel fiber }\end{cases}
$$

Eq. (36) implies that the strain capacity of the composite is composed of two parts: the contribution from the matrix $\varepsilon_{u}$ and the contribution from the fibers $K V_{f} \ell / d_{f}$. It is therefore evident that

$$
\begin{aligned}
& \text { (3) } \alpha_{1}=\alpha_{1 m}=\frac{K V_{f} \ell / d_{f}}{\varepsilon_{c a} \cdot} \\
& \text { (4) } \alpha_{2}=\alpha_{2 m}=\frac{\varepsilon_{u}}{\varepsilon_{c a}}
\end{aligned}
$$

in which

$$
\alpha_{1}+\alpha_{2}=1
$$

is implied.

The deformation contribution of the matrix, after the matrix cracks, will largely come from the post-peak opening of the crack (softening regime of the stress-strain 
curve). However, as has been examined by Balagura and Shah (1992), the response of the matrix in an FRC varied with the content and type of the reinforcement. Therefore, it is rational to assume, based on the assumption of the fictive ultimate strain, as shown in Fig. 2, that

$$
\alpha_{2}=g \cdot \frac{\varepsilon_{u}-\varepsilon_{m}}{\varepsilon_{u}-\varepsilon_{t}}=\frac{\varepsilon_{m}}{\varepsilon}
$$

where $g$ is a constant dependent on the fiber volume fraction $V_{f}$ and the type of the fiber used in the FRC, which has to be determined from experimental results. In this study, it is obtained that

$$
g=\left\{\begin{aligned}
2.05-2.5 V_{f} & \text { for Dramix I steel fiber, } V_{f} \leqslant 9 \% \\
3.85-45.0 V_{f} & \text { for Dramix II steel fiber, } V_{f} \leqslant 5 \%
\end{aligned}\right.
$$

Therefore, strain in the matrix $\varepsilon_{m}$ can be estimated by

$$
\varepsilon_{m}=\frac{\varepsilon_{u}}{1+\frac{\varepsilon_{u}-\varepsilon_{t}}{g \varepsilon}}
$$

which implies that when $\varepsilon=\varepsilon_{t}$, and $g=1$, then $\alpha_{2}=1$. Whereas when $\varepsilon=\varepsilon_{c a} \gg$ $\left(\varepsilon_{u}-\varepsilon_{t}\right), \varepsilon_{m} \approx \varepsilon_{u}$, and $\alpha_{2} \approx \alpha_{2 m}$. Thus it meets the boundary conditions (Eqs. (35) and (38)), if $g$ is set at 1 when $\varepsilon \leqslant \varepsilon_{t}$.

Eqs. (40) and (42) implies that

$$
\alpha_{2}=\frac{\varepsilon_{u}}{\varepsilon+\frac{\varepsilon_{u}-\varepsilon_{t}}{g}}
$$

Therefore, from Eq. (39), we have

$$
\alpha_{1}=\frac{g \varepsilon+(1-g) \varepsilon_{u}-\varepsilon_{t}}{g \varepsilon+\varepsilon_{u}-\varepsilon_{t}}
$$


The coefficient $\alpha_{10}$ and initial debonding strain $\varepsilon_{0}^{f}$ can then be evaluated as follows. From Eq. (44), we have

$$
\alpha_{10}=\frac{g \varepsilon_{0}^{f}+(1-g) \varepsilon_{u}-\varepsilon_{t}}{g \varepsilon_{0}^{f}+\varepsilon_{u}-\varepsilon_{t}}
$$

Eq. (19) can be rewritten as

$$
\alpha_{10} \varepsilon_{0}^{f}=\frac{2 q_{f} D}{L E_{f} A \psi^{2}}
$$

Thus, $\alpha_{10}$ and $\varepsilon_{0}^{f}$ can then be obtained numerically by solving an equation combining Eqs. (45) and (46).

\section{$5 \quad$ Numerical Results}

The constitutive model characterized by Eq. (8) for the prediction of tensile stressstrain curves of FRC containing Dramix steel fibers shows strain hardening responses, was tested against the experimental results obtained in this study. Parameters needed for the model are given to a large extent in the previous sections. Some of them, calculated by the corresponding equations, are given in Table 3. Comparison between the model predicted stress-strain relationship and that obtained from experimental investigations are shown in Figs. 3, 4, and 5, for FRC containing Dramix type I steel fiber at a $V_{f}$ of $6 \%, 7 \%$, and $8 \%$, respectively. Those for FRCs containing Dramix type II steel fibers are shown in Figs. 6, 7, and 8, at a fiber volume fraction of $3 \%, 3.5 \%$, and $4 \%$, respectively. Parameters related to the fiber-matrix interface $(\psi, k$ and $\Gamma)$ are selected based on results from references. Those related to the matrix are determined experimentally ( $\mathrm{Li}$ et al., 1998; $\mathrm{Li}, 1998$ ). Note that only the hardening regime of the composite response are plotted in these figures.

These figures show a good agreement between the experimental results and the model predicted results, except for FRC containing Dramix type II steel fibers at a 
$V_{f}=3 \%$ and $3.5 \%$. At a comparatively lower fiber content, the post-cracking behavior of a composite will be dominated by the fiber pull-out from the matrix along the transverse crack. For Dramix type II steel fibers, anchorage effect provided by the hooked ends is not quite understood, thus not incorporated in the model, which may be reflected in the model predicted results.

\section{Summary and Conclusions}

In this paper, an analytical model for the tensile behavior of an FRC shows a strain hardening response is developed based on the principles of the continuum damage mechanics. Assuming a parallel bar model in which the fibers and the concrete were connected by parallel-series components, an equilibrium equation was established for the FRC. By taking two damage measures related to the matrix and to the fibers respectively, a continuum form of the equation was then established. The evolution of the two measures of damage was then evaluated in detail. The fiber-matrix interface properties are incorporated explicitly in the model.

A good agreement between the model predicted stress-strain curves and the experimentally obtained shows that the analytical model derived from the principles of the continuum damage mechanics is quite successful. The model requires the knowledge of the matrix (five parameters) and of the fiber-matrix interface properties (three parameters), which has to be determined experimentally.

\section{Acknowledgments}

This research is sponsored by the Research Grants Council of the Hong Kong Government under the grant HKUST641/95E which is gratefully acknowledged. 


\section{References}

Aveston, J., Cooper, G. A. and Kelly, A. 1971. Single and multiple fracture, The Properties of Fiber Composites, National Physical Laboratory, IPC Science and Technology Press Ltd., pp. 15-26.

Balaguru, P. N. and Shah, S. P. 1992. Fibre Reinforced Cement Composites, McGrawHill Book Co., New York.

Bentur, A. and Mindess, S. 1990. Fibre Reinforced Cementitious Composites, Elsevier Applied Science, London.

Borderie, C. L., Mazars, J. and Pijaudier-Cabot, G. 1992. Response of plain and reinforced concrete structures under cyclic loadings, Concrete Design Based on Fracture Mechanics, ACI Publication SP-134, Edited by Walter Gerstle and Zdeněk P. Bažant, American Concrete Institute, pp. 147-172.

Fanella, D. and Krajcinovic, D. 1985. Continuum damage mechanics of fiber reinforced concrete, Journal of Engineering Mechanics, ASCE 111(8): 995-1009.

Gray, R. J. 1984. Analysis of the effect of embedded fiber length on fiber debonding and pull-out from an elastic matrix. Part 2: Application to a steel fibre-cementitious matrix composite system, Journal of Materials Science 19: 1680-1691.

Hannant, D. J. 1978. Fibre Cements and Fibre Concretes, John Wiley \& Sons, Chichester.

Hull, D. and Clyne, T. W. 1996. An Introduction to Composite Materials, Cambridge Solid State Science Series, second edition, Cambridge University Press, Cambridge.

Karihaloo, B. L. and Fu, D. 1990a. An anisotropic damage model for plain concrete, Engineering Fracture Mechanics 35(1/2/3): 205-209.

Karihaloo, B. L. and Fu, D. 1990b. An orthotropic damage model for plain concrete in tension, ACI Materials Journal 87(1): 62-67.

Kimber, A. C. and Keer, J. G. 1982. On the theoretical average crack spacing in brittle matrix composites containing continuous aligned fibers, Journal of Materials Science Letters 1: 353-354.

Krajcinovic, D. and Silva, M. A. G. 1982. Statistical aspects of the continuous damage theory, International Journal of Solids and Structures 18(7): 551-562. 
Li, F. 1998. Fracture Characterization of Fiber Reinforced Concrete in Direct Uniaxial Tension, Ph. D dissertation, Hong Kong University of Science and Technology, Clear Water Bay, Kowloon, Hong Kong.

$\mathrm{Li}, \mathrm{F}$. and $\mathrm{Li}, \mathrm{Z}$. 1999. Acoustic emission from fiber reinforced concrete in direct tension. submitted to ACI Materials Journal.

Li, S. H., Li, Z., Mura, T. and Shah, S. P. 1992. Multiple fracture of fiber reinforced brittle matrix composites based on micromechanics, Engineering Fracture Mechanics 43(4): 561-579.

Li, V. C. and Leung, C. K. Y. 1992. Theory of steady state and multiple cracking of random discontinuous fiber reinforced brittle matrix composites, Journal of Engineering Mechanics, ASCE 118(11): 2246-2264.

Li, Z., Li, F., Chang, T.-Y. P. and Mai, Y.-W. 1998. Uniaxial tensile behavior of concrete reinforced with randomly distributed short fibers, ACI Materials Journal 95(5): 564-574.

Li, Z., Mobasher, B. and Shah, S. P. 1991. Characterization of interfacial properties in fiber reinforced cementitious composites, Journal of American Ceramic Society $74(9): 2156-2164$.

Løland, K. E. 1980. Continuous damage model for load-response estimation of concrete, Cement and Concrete Research 10: 395-402.

Mazars, J. and Pijaudier-Cabot, G. 1989. Continuum damage theory - application to concrete, Journal of Engineering Mechanics, ASCE 115(2): 420-428.

Naaman, A. E. and Homrich, J. R. 1989. Tensile stress strain properties of SIFCON, ACI Materials Journal 86(3): 244-251.

Pompo, A., Stupak, P. R., Nicolais, L. and Marchese, B. 1996. Analysis of steel fibre pull-out from a cement matrix using video photography, Cement and Concrete Composites 18(1): 3-8.

Shah, S. P., Swartz, S. E. and Ouyang, C. 1995. Fracture Mechanics of Concrete: Applications of Fracture Mechanics to Concrete, Rock, and Other Quasi-Brittle Materials, John Wiley \& Sons, Inc., New York. 
Stang, H., Li, Z. and Shah, S. P. 1990. Pull-out problem: Stress versus fracture mechanical approach, Journal of Engineering Mechanics, ASCE 116(10): 21362150.

Stang, H., Tonnesen, M. and Byskov, E. 1990. CDM based constitutive equations for high strength and fiber reinforced concrete, in S. P. Shah, S. E. Swartz and M. L. Wang (eds), Micromechanics of Failure of Quasi-Brittle Materials, Proceedings of the International Conference on Micromechanics of Failure of Quasi-Brittle Materials, Albuquerque, New Mexico, USA, Elsevier Applied Science, London, pp. 589-599.

Zollo, R. F. 1997. Fiber reinforced concrete: an overview after 30 years of development, Cement and Concrete Composites 19: 107-122. 


\section{Appendix 1}

\section{Notations}

$A \quad\left(\mathrm{~m}^{2}\right)=$ cross-sectional area of the fiber

$A_{c} \quad\left(\mathrm{~m}^{2}\right)=$ initial cross-sectional area of the FRC specimen

$A_{m} \quad\left(\mathrm{~m}^{2}\right) \quad=$ initial cross-sectional area of the matrix

a (m) = debonded length of the fiber-matrix interface

$B_{1} \quad(-)=$ a coefficient defined by Eq. (11)

$B_{2} \quad(-) \quad=$ a coefficient defined by Eq. (11)

$D \quad(-) \quad=$ a dimensionless constant defined by Eq. (16)

$D_{\max }(\mathrm{m})=$ extension of the fracture zone in a matrix concrete

$d_{f} \quad(\mathrm{~m}) \quad=$ diameter of the fiber

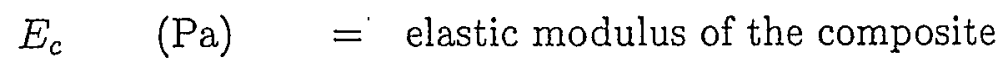

$E_{f} \quad(\mathrm{~Pa}) \quad=$ elastic modulus of the fiber

$E_{m} \quad(\mathrm{~Pa}) \quad=$ elastic modulus of the matrix

$E_{m 0}(\mathrm{~Pa}) \quad=$ elastic modulus of the uncracked matrix

$F \quad(\mathrm{~N}) \quad=$ externally applied force

$f_{i} \quad(N)=$ force in composite bar

$f_{m} \quad(\mathrm{~N}) \quad=$ force in the matrix at which matrix damage is initiated

$f_{m t}(\mathrm{~N} / \mathrm{m})=$ tensile strength of the matrix

$g \quad(-)=$ a constant related to fiber type and fiber content, appeared in Eq. (40)

$K \quad(-) \quad=$ a dimensionless constant related to fiber type

$k^{\prime}\left(\mathrm{N} / \mathrm{m}^{2}\right)=$ fiber-matrix interface shear stiffness

$k_{c} \quad(\mathrm{~N} / \mathrm{m})=$ overall stiffness of the composite cross-section

$k_{d}(\mathrm{~N} / \mathrm{m})=$ stiffness of the damaged composite bar

$k_{f}^{\prime}(\mathrm{N} / \mathrm{m})=$ equivalent stiffness of the fiber in an FRC

$k_{m} \quad(\mathrm{~N} / \mathrm{m})=$ stiffness of the damaged matrix

$k_{m 0}(\mathrm{~N} / \mathrm{m})=$ stiffness of the uncracked matrix

$L \quad(\mathrm{~m}) \quad=$ average crack spacing for composite showing multiple cracking response, or length of the specimen for composite showing single cracking response

$\ell \quad(m)=$ length of the fiber

$\ell_{c} \quad(\mathrm{~m})=$ critical length of the fiber

$\ell_{e} \quad(\mathrm{~m})=$ embedment length of the fiber

$\bar{\ell}_{e} \quad(\mathrm{~m}) \quad=$ mean embedment length of the fiber 


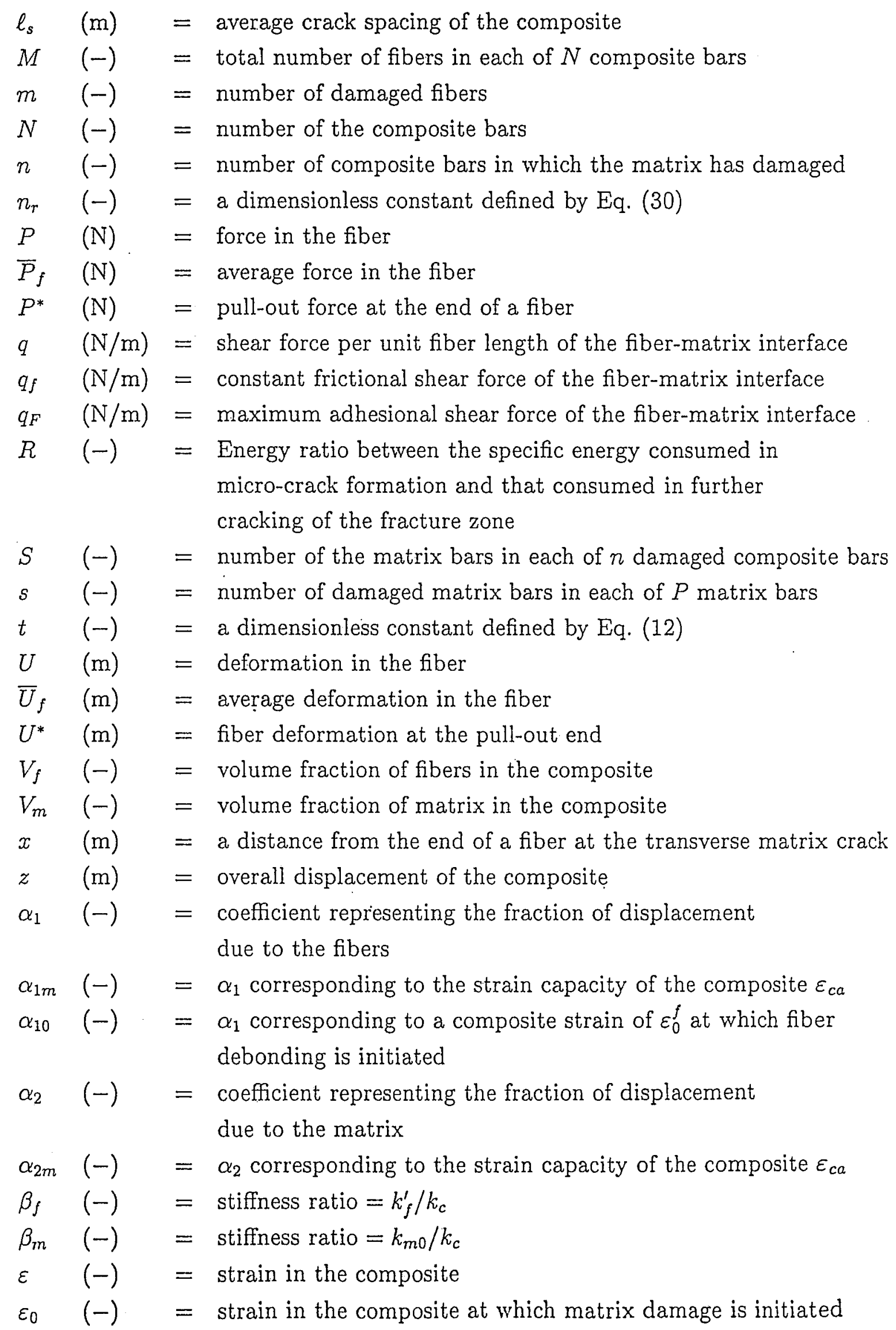


$\varepsilon_{0}^{f} \quad(-)=$ strain in the composite at which fiber debonding is initiated

$\varepsilon_{c a}(-)=$ strain capacity of the FRC

$\varepsilon_{m}(-)=$ strain in the matrix concrete

$\varepsilon_{t} \quad(-)=$ strain in the matrix concrete corresponding to the tensile strength

$\varepsilon_{u}(-)=$ ultimate strain in the matrix concrete

$\zeta \quad(-)=$ a dimensionless constant defined by Eq. (12)

$\eta \quad(-)=$ the length efficiency factor of a fiber

$\Gamma\left(\mathrm{m}^{-1}\right)=$ critical energy release rate of the fiber-matrix interface

$\gamma \quad(-)=$ a coefficient defined by Eq. (28)

$\nu_{m}(-) \quad=$ Poisson's ratio of the matrix concrete

$\xi \quad(-)=$ a dimensionless constant defined by Eq. (11)

$\sigma(\mathrm{Pa})=$ nominal stress in the composite

$\sigma_{m}(\mathrm{~Pa})=$ nominal stress in the matrix concrete

$\sigma_{f u}(\mathrm{~Pa})=$ ultimate stress of the fiber

$\tau(\mathrm{Pa})=$ frictional shear stress of the fiber-matrix interface

$\tau_{f u}(\mathrm{~Pa})=$ frictional bond strength of the fiber-matrix interface

$\omega_{c}(-)=$ measure of damage related to matrix concrete

$\omega_{c t}(-)=$ damage of matrix concrete corresponding to its tensile strength

$\omega_{f}(-)=$ measure of damage related to fibers

$\omega_{f c}(-)=$ critical damage value related to fibers 


\section{List of Tables}

1 Summary of the properties of the fibers used in the study $\ldots \ldots \ldots \ldots \ldots 26$

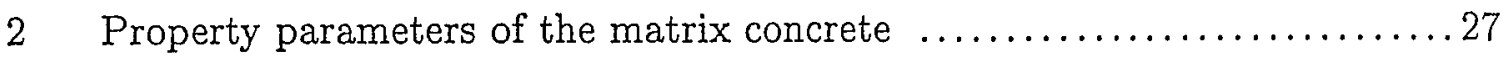

3 Summary of the numerical results from the analytical model ........... 28

\section{List of Figures}

1 Schematic diagram showing the parallel bar model. $\ldots \ldots \ldots \ldots, \ldots \ldots \ldots 29$

2 Evolution of damage $\omega_{c}(a)$ and nominal stress (b) related to strain for

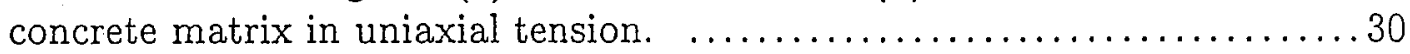

3 Tensile stress-strain curves for FRC containing 6\% Dramix type I steel fibers: comparison of the experimental results with model predicted.

4 Tensile stress-strain curves for FRC containing 7\% Dramix type I steel fibers: comparison of the experimental results with model predicted. . ....32

5 Tensile stress-strain curves for FRC containing $8 \%$ Dramix type I steel fibers: comparison of the experimental results with model predicted. . ...33

6 Tensile stress-strain curves for FRC containing 3\% Dramix type II steel fibers: comparison of the experimental results with model predicted. ....34

7 Tensile stress-strain curves for FRC containing 3.5\% Dramix type II steel fibers: comparison of the experimental results with model predicted. . ....35

8 Tensile stress-strain curves for FRC containing 4\% Dramix type II steel fibers: comparison of the experimental results with model predicted. . ...36 
Table 1 Summary of the properties of the fibers used in the study

\begin{tabular}{|l|l|c|c|c|c|c|c|}
\hline Fiber name & Fiber type & $\begin{array}{c}\ell \\
(\mathrm{mm})\end{array}$ & $\begin{array}{c}d_{f} \\
(\mathrm{~mm})\end{array}$ & $\ell / d_{f}$ & $\begin{array}{c}\text { Density } \\
\left(\mathrm{g} / \mathrm{cm}^{3}\right)\end{array}$ & $\begin{array}{c}\text { Tensile } \\
\text { Strength } \\
(\mathrm{GPa})\end{array}$ & $\begin{array}{c}\text { Young's } \\
\text { Modulus } \\
(\mathrm{GPa})\end{array}$ \\
\hline Dramix I & Steel & 30 & 0.5 & 60 & 7.8 & 1.2 & 200 \\
\hline Dramix II & Steel & 50 & 0.5 & 100 & 7.8 & 1.2 & 200 \\
\hline
\end{tabular}

Note: $\quad \ell=$ fiber length;

$d_{f}=$ fiber diameter;

$\ell / d_{f}=$ fiber aspect ratio. 
Table 2 Property parameters of the matrix concrete

\begin{tabular}{|l|c|c|c|c|c|}
\hline \multicolumn{1}{|c|}{ Parameters } & $\begin{array}{c}f_{m t} \\
(\mathrm{MPa})\end{array}$ & $\begin{array}{c}E_{m 0} \\
(\mathrm{GPa})\end{array}$ & $\begin{array}{c}\varepsilon_{t} \\
(\mu \mathrm{m} / \mathrm{m})\end{array}$ & $\begin{array}{c}\varepsilon_{0} \\
(\mu \mathrm{m} / \mathrm{m})\end{array}$ & $\begin{array}{c}\varepsilon_{u}^{\dagger} \\
(\mu \mathrm{m} / \mathrm{m})\end{array}$ \\
\hline average & 3.97 & 28.86 & 148.30 & 48.80 & 406.3 \\
\hline standard deviation & 0.17 & 2.40 & 7.8 & 5.1 & 45.8 \\
\hline $\begin{array}{l}\text { coefficient of } \\
\text { variation (\%) }\end{array}$ & 5 & 8 & 6 & 11 & 12 \\
\hline
\end{tabular}

$\dagger$ based on Eq. (13) 
Table 3 Summary of the numerical results from the analytical model

\begin{tabular}{|c|c|r|r|r|r|r|r|l|}
\hline \multirow{2}{*}{$\begin{array}{c}\text { Para- } \\
\text { meters }\end{array}$} & \multirow{2}{*}{ Unit } & \multicolumn{3}{|c|}{ Dramix I fiber $\left(V_{f}\right)$} & \multicolumn{2}{|c|}{ Dramix II fiber $\left(V_{f}\right)$} & \multirow{2}{*}{ Comments } \\
\cline { 3 - 8 } & $6 \%$ & $7 \%$ & $8 \%$ & $3 \%$ & $3.5 \%$ & $4 \%$ &. \\
\hline$\beta_{f}$ & - & 0.0453 & 0.0443 & 0.0433 & 0.0664 & 0.0656 & 0.0649 & Eq. (24) \\
\hline$\beta_{m}$ & - & 0.8778 & 0.8588 & 0.8402 & 0.9357 & 0.9253 & 0.9151 & Eq. (25) \\
\hline$E_{c}$ & $\mathrm{GPa}$ & 30.903 & 31.251 & 31.600 & 29.919 & 30.097 & 30.276 & Eq. (26) \\
\hline$\ell_{c}$ & $\mathrm{~mm}$ & 78.95 & 78.95 & 78.95 & 78.95 & 78.95 & 78.95 & Eq. (33) \\
\hline$L$ & $\mathrm{~mm}$ & 22.61 & 19.18 & 16.60 & 28.00 & 23.88 & 20.79 & Eq. (32) \\
\hline$\omega_{f c}$ & - & 0.8024 & 0.8024 & 0.8024 & 0.8168 & 0.8168 & 0.8168 & Eq. (34) \\
\hline$\varepsilon_{c a}$ & $10^{-3}$ & 3.970 & 4.564 & 5.158 & 3.856 & 4.431 & 5.006 & Eq. (36) \\
\hline
\end{tabular}




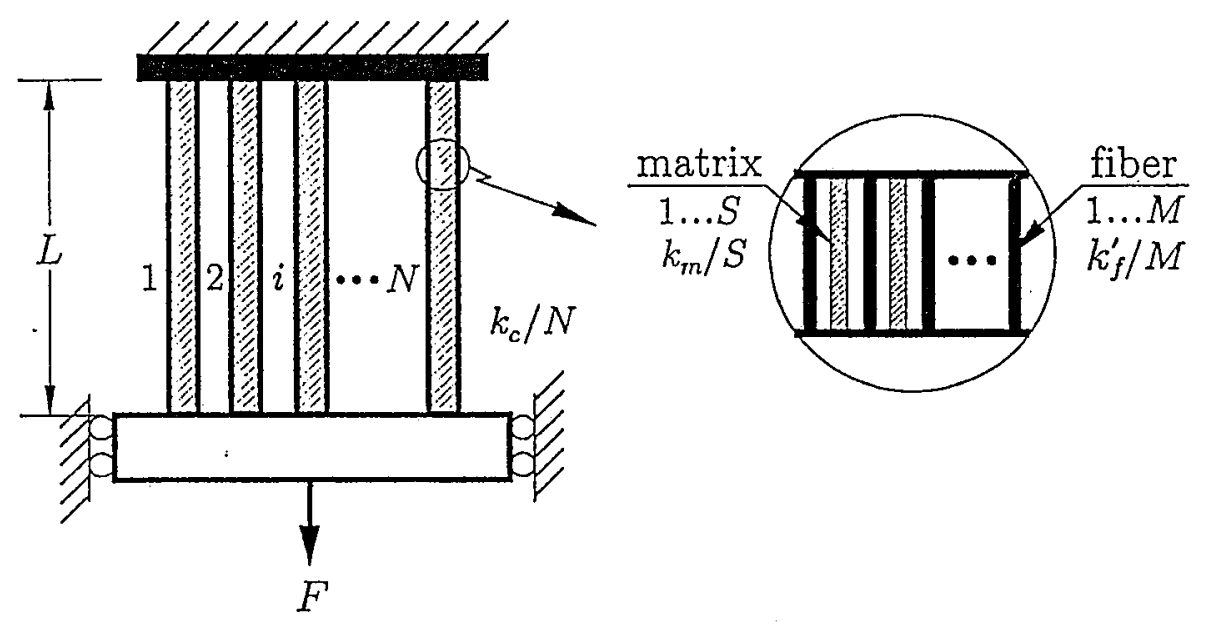

Figure 1 Schematic diagram showing the parallel bar model. 


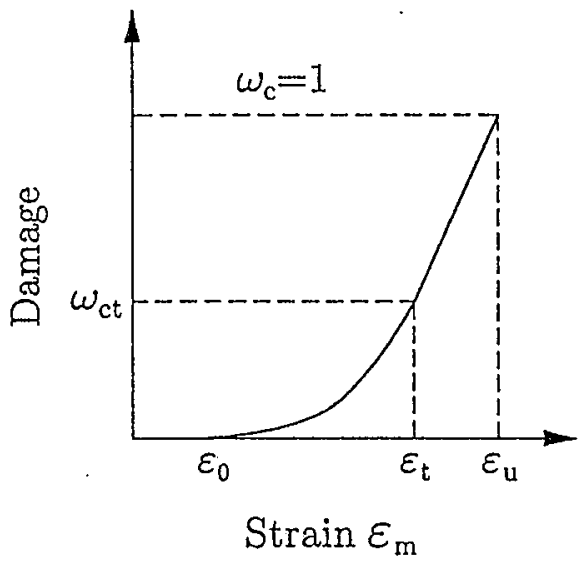

(a)

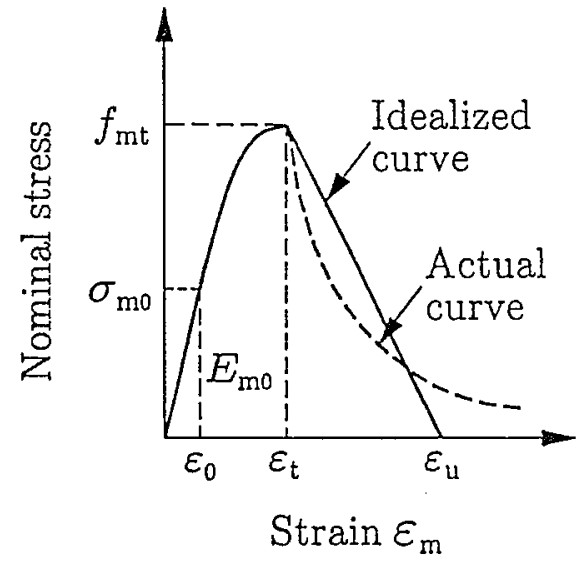

(b)

Figure 2 Evolution of damage $\omega_{c}$ (a) and nominal stress (b) related to strain for concrete matrix in uniaxial tension. 


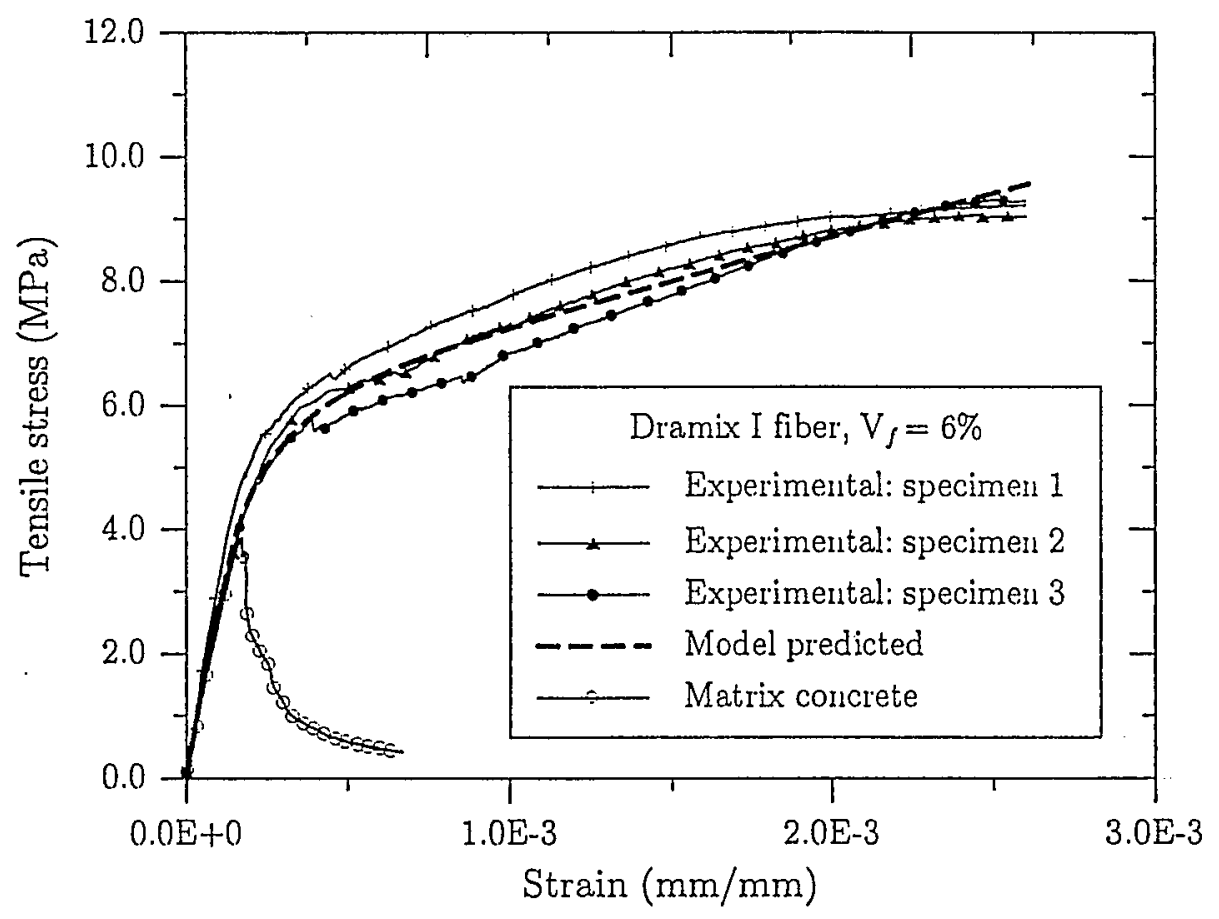

Figure 3 Tensile stress-strain curves for FRC containing 6\% Dramix type I steel fibers: comparison of the experimental results with model predicted. 


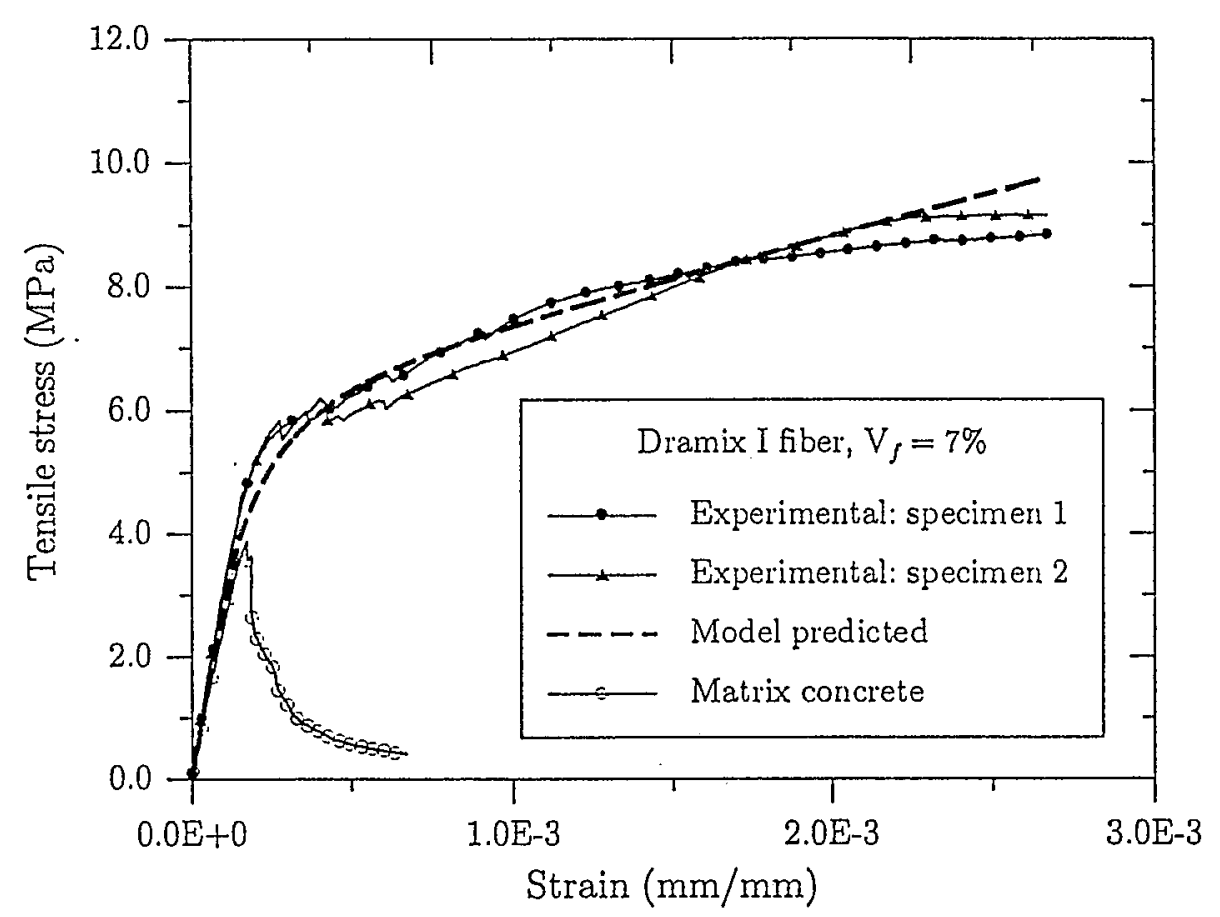

Figure 4 Tensile stress-strain curves for FRC containing 7\% Dramix type I steel fibers: comparison of the experimental results with model predicted. 


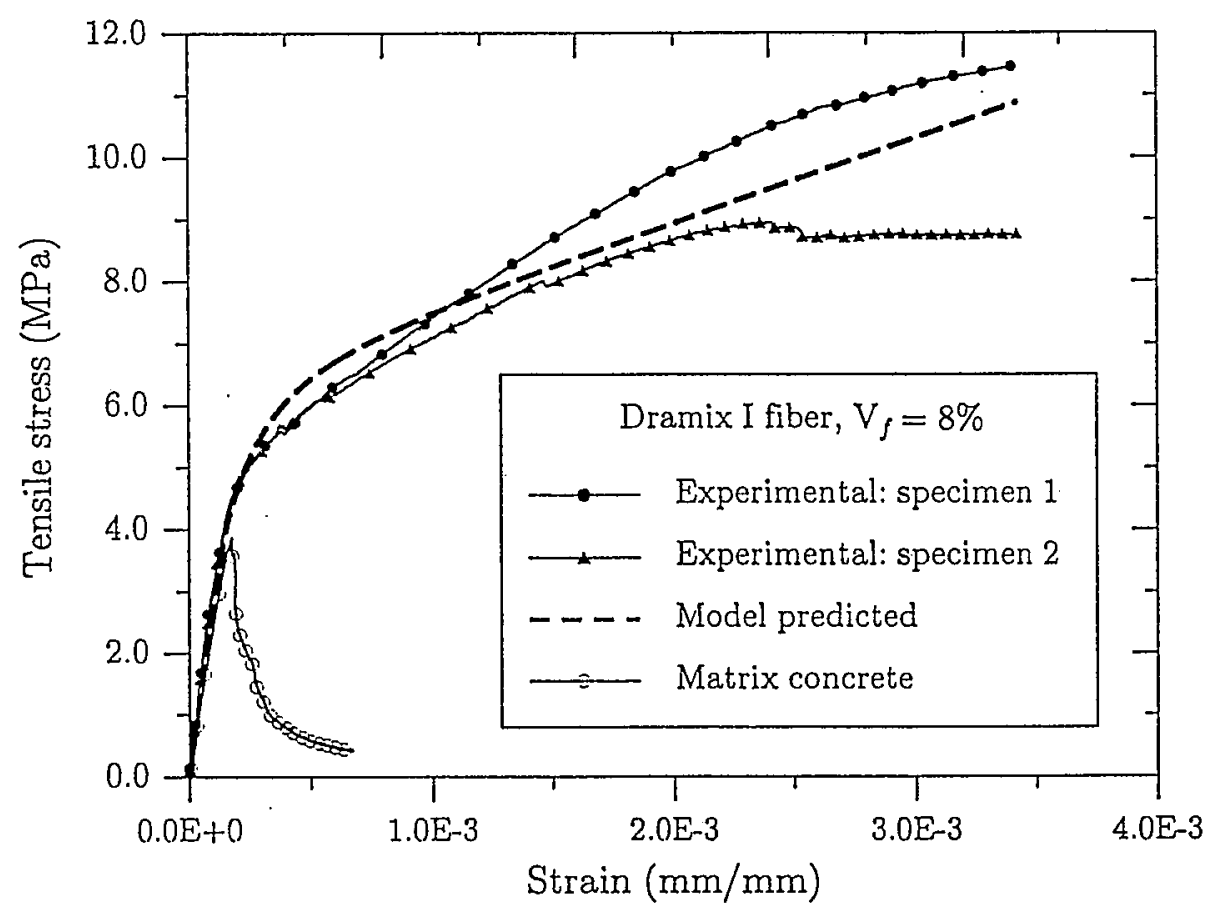

Figure 5 Tensile stress-strain curves for FRC containing 8\% Dramix type I steel fibers: comparison of the experimental results with model predicted. 


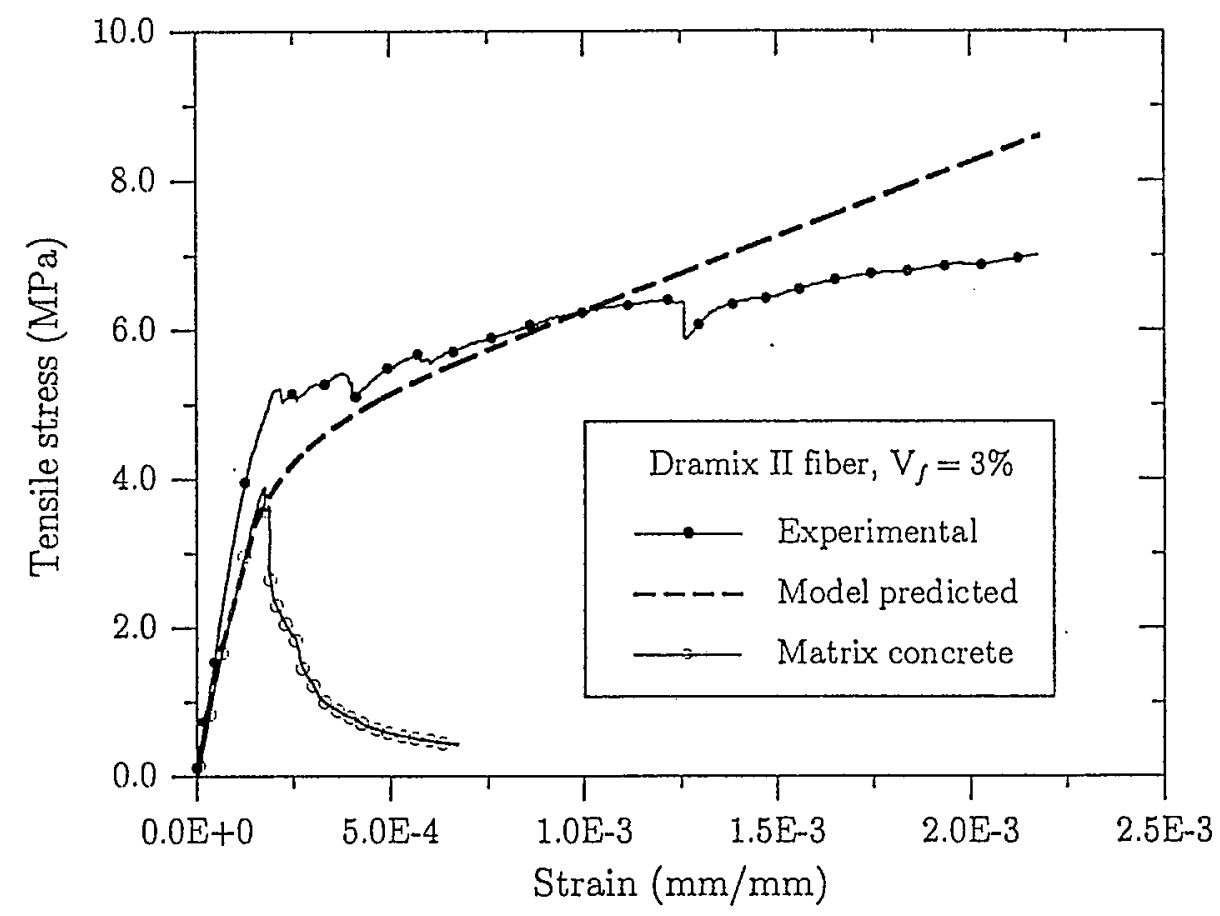

Figure 6 Tensile stress-strain curves for FRC containing 3\% Dramix type II steel fibers: comparison of the experimental results with model predicted. 


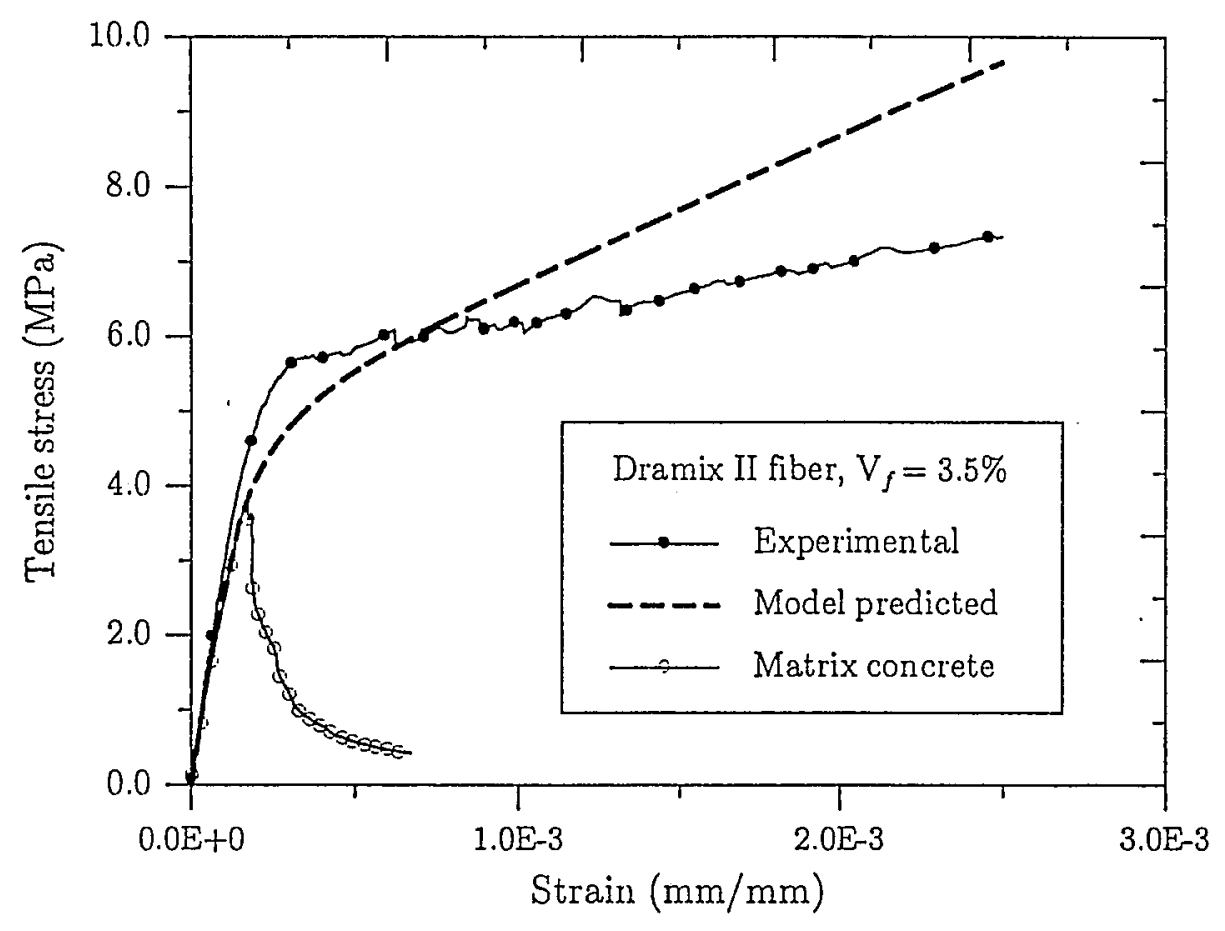

Figure 7 Tensile stress-strain curves for FRC containing 3.5\% Dramix type II steel fibers: comparison of the experimental results with model predicted. 


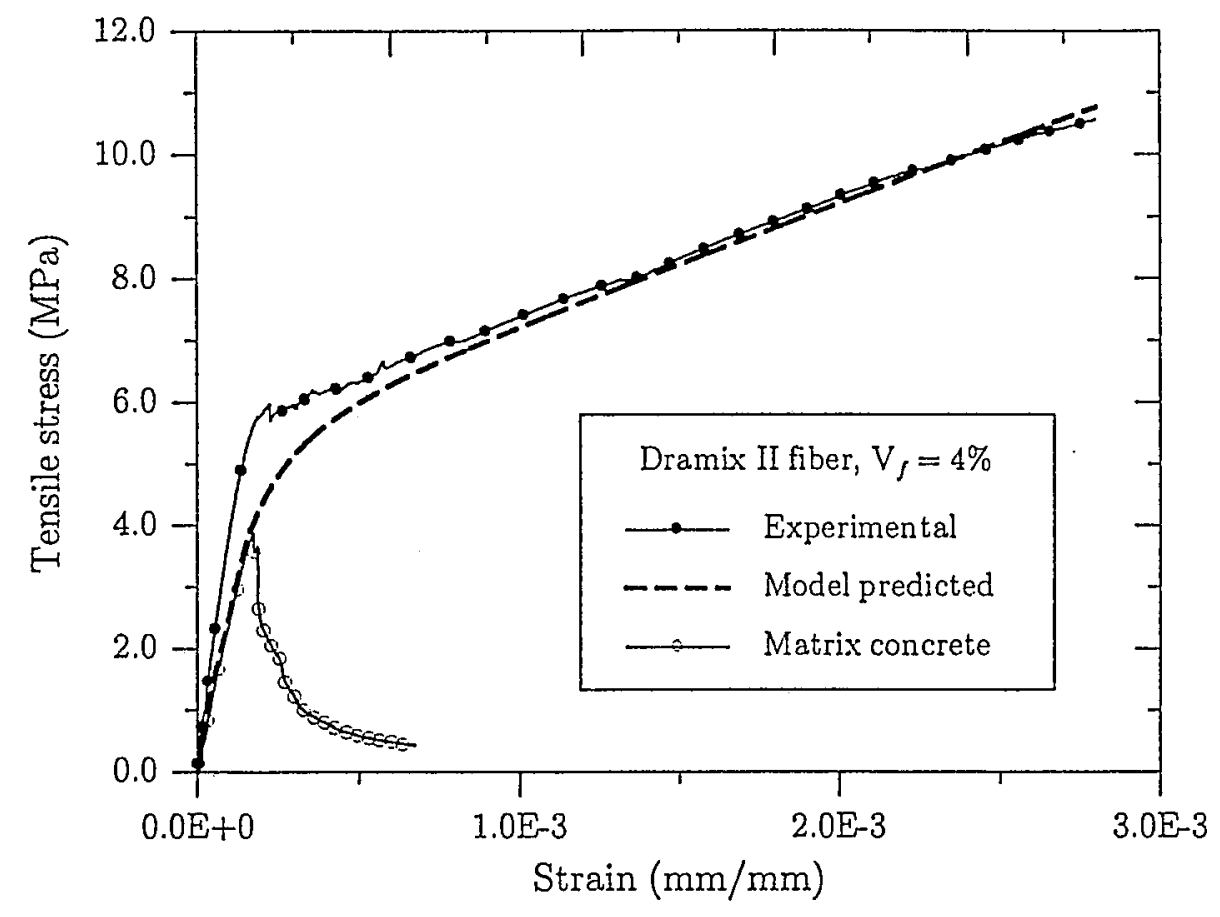

Figure 8 Tensile stress-strain curves for FRC containing 4\% Dramix type II steel fibers: comparison of the experimental results with model predicted. 